\title{
Desempenho agronômico de variedades crioulas e híbridos de milho cultivados em diferentes sistemas de manejo ${ }^{1}$
}

\author{
Agronomic performance of landrace and hybrid maize varieties cultivated under \\ different management systems
}

\author{
Alisson Vinicius de Araujo ${ }^{2 *}$, Delacyr da Silva Brandão Junior ${ }^{3}$, Izabel Cristina Pereira Vaz Ferreira² ${ }^{2}$, Cândido \\ Alves da Costa $^{3}$ e Bruna Béssel Almeida Porto ${ }^{3}$
}

\begin{abstract}
RESUMO - Apesar das variedades crioulas favorecerem a autonomia no processo produtivo na agricultura familiar, tem-se observado o seu abandono ao elevar-se o nível tecnológico empregado na lavoura, acreditando-se que apenas os cultivares modernos apresentam retorno econômico. Dessa forma, o objetivo deste trabalho foi verificar a influência de diferentes sistemas tecnológicos de manejo sobre os caracteres agronômicos de milho, provenientes de duas variedades crioulas ('Argentino' e 'BR da Várzea') e de dois híbridos. Os sistemas de manejo foram classificados como baixo, médio e alto nível tecnológico. O experimento foi conduzido em esquema fatorial $4 \times 3$ (quatro genótipos de milho e três sistemas tecnológicos de manejo), em delineamento em blocos completos casualizados, em faixas, com três repetições. Avaliaram-se a emergência, a incidência de Spodoptera frugiperda (lagarta-do-cartucho), a precocidade e a sincronia do florescimento, plantas acamadas, o diâmetro do colmo, a altura da planta e da inserção da espiga, o estande final e a produtividade. O desempenho agronômico das variedades crioulas foi maximizado pelo incremento tecnológico, tanto quanto os híbridos. Práticas de manejo acessíveis, como a utilização de adubação orgânica e o controle alternativo de pragas, são capazes de maximizar a produção de grãos de milho.
\end{abstract}

Palavras-chave: Agricultura familiar. Produção orgânica. Manejo do solo. Sustentabilidade. Zea mays.

\begin{abstract}
Despite landrace varieties favouring autonomy in the production process in family farming, their use has been neglected with the rise in the level of technology employed in agriculture, where it is believed that only modern cultivars present an economic return. The objective of this study therefore was to investigate the influence of different technological management systems on the agronomical characteristics of maize from two landrace varieties ('Argentine' and 'BR da Várzea') and from two hybrids. The management systems were classified as being of a low, medium and high technological level. The experiment was carried out in a $4 \times 3$ factorial (four maize genotypes and three technological management systems) in a complete randomized block design, in strips and with three replications. The following were evaluated: emergence, incidence of Spodoptera frugiperda (armyworm), flowering precocity and synchrony, plant bedding, stem diameter, plant and ear height, final growth and productivity. The agronomical performance of both the landrace varieties and the hybrids were maximized by technological advances. Affordable management practices, such as the use of organic fertilizers and alternative pest-control, are able to maximize the production of maize.
\end{abstract}

Key words: Family farming. Organic production. Soil management. Sustainability. Zea mays.

\footnotetext{
*Autor para correspondência

'Recebido para publicação em 09/09/2012; aprovado em 16/06/2013

Parte de Dissertação de Mestrado do primeiro autor apresentada ao Programa de Pós-Graduação em Ciências Agrárias da Universidade Federal de Minas Gerais/UFMG

2Programa de Pós-Graduação em Fitotecnia, Departamento de Fitotecnia, Universidade Federal de Viçosa, Viçosa-MG, Brasil, viniciusnca@ yahoo.com.br, izabelcpvf@yahoo.com.br

${ }^{3}$ Instituto de Ciências Agrárias, Universidade Federal de Minas Gerais, Montes Claros-MG, Brasil, dsbrandaojr@ufmg.br, candido-costa@ ufmg.br, bubessell@hotmail.com
} 


\section{INTRODUÇÃO}

Por meio de um processo de observação e de seleção, e conforme preferências e valores culturais específicos de cada local, os agricultores chegaram às variedades crioulas, portadoras de alta rusticidade e adaptadas às condições adversas de solo e de clima e ao sistema de manejo empregado na agricultura familiar. Esses materiais detêm combinações alélicas importantes e a substituição desses por cultivares modernos, como tem acontecido desde a década de 1950, não apenas vem gerando o processo de erosão genética, como também ameaça o conhecimento tradicional de cultivos peculiares (BOEF, 2007).

É comum verificar o abandono das variedades crioulas pelos agricultores, ao elevarem o nível tecnológico empregado na lavoura, até mesmo quando se utilizam técnicas mais acessíveis, tais como a adubação orgânica, o emprego de implementos por tração animal ou a aplicação de caldas naturais para o manejo fitossanitário, acreditando-se que apenas os cultivares modernos apresentam retorno econômico que justifique a utilização dessas técnicas.

Para Meneguetti, Girardi e Reginatto (2002), o uso de milhos crioulos ou variedades melhoradas é viável técnica e economicamente, com desempenho semelhante ou até mesmo superior das variedades crioulas em relação às variedades comerciais e híbridos. Segundo ainda Meneguetti, Girardi e Reginatto (2002), o desempenho satisfatório de algumas variedades não invalida os esforços na busca de melhoria da fertilidade de solo, infraestrutura e condições para melhorar a produção.

Alguns trabalhos comprovam que, quanto maior o investimento em práticas de manejo, maior será a produtividade do milho (FORSTHOFER et al., 2006; RIBEIRO et al., 2005; SANGOI et al., 2003). Porém, as técnicas de produção empregadas nesses agroecossistemas, frente à crescente demanda por fontes não renováveis, à elevação de custos de produção e à redução dos preços dos produtos, podem resultar em cenários que comprometam a sustentabilidade dessa atividade.

O estudo do comportamento e do potencial produtivo de variedades crioulas e de híbridos de milho cultivados em agroecossistemas diferenciados é uma ferramenta relevante para a tomada de decisões na condução da lavoura por agricultores e técnicos. Assim, objetivou-se com este trabalho verificar a influência de diferentes sistemas tecnológicos de manejo sobre os caracteres agronômicos de milho, provenientes de variedades crioulas ('Argentino' e 'BR da Várzea') e de dois híbridos.

\section{MATERIAL E MÉTODOS}

O trabalho foi conduzido no período de novembro de 2009 a abril de 2010, em Montes Claros/MG (latitude $16^{\circ} 43^{\prime} \mathrm{S}$, longitude $43^{\circ} 53^{\prime} \mathrm{W}$ e altitude $650 \mathrm{~m}$ ), região de clima Aw (tropical de savana, inverno seco e verão chuvoso) pelo sistema Köppen. Durante a condução do experimento, a temperatura variou entre 20,3 e $31,8^{\circ} \mathrm{C}$, com uma média de $26,85{ }^{\circ} \mathrm{C}$. A umidade relativa do ar variou entre 26,0 e $98,0 \%$, com uma média de $63,67 \%$. Foram determinados os atributos químicos e texturais na camada de $0-20 \mathrm{~cm}$ do solo, onde se implantaram os sistemas de manejo (Tabela 1).

$\mathrm{O}$ experimento foi conduzido em esquema fatorial 4x3 (quatro genótipos de milho e três sistemas tecnológicos de manejo), em delineamento de blocos completos casualizados, cujo critério de bloqueamento foi a declividade do terreno. Além disso, adotou-se o experimento em faixa, escolhido por questões de ordem operacional visando dispor o fator genótipos manejados em cada nível tecnológico. Nas faixas horizontais foram testados os sistemas tecnológicos de manejo e, nas faixas verticais, os genótipos de milho. A casualização dos tratamentos nas parcelas foi feita segundo recomendação de Zimmermann (2004). A distribuição dos tratamentos às parcelas foi feita de forma sequencial, sorteando-se primeiro os níveis tecnológicos às parcelas constituídas no sentido horizontal e, em seguida, os genótipos às parcelas formadas num sentido vertical. Utilizaram-se três repetições. As unidades experimentais foram constituídas por quatro linhas de $5 \mathrm{~m}$ de comprimento, espaçadas em $0,80 \mathrm{~m}$, sendo a parcela útil composta pelas duas linhas centrais, desprezando-se um metro em cada extremidade. Após 21 dias, realizou-se o desbaste das plantas, ajustando-se a densidade de plantas para 62.500 plantas ha $^{-1}$.

Os genótipos consistiram em duas variedades crioulas tradicionalmente cultivadas na região Norte de Minas Gerais, denominadas pelos agricultores de 'Argentino' e de 'BR da Várzea', um híbrido duplo (SHS 4080) e um híbrido simples (IAC 8333).

Os sistemas de manejo empregados na pesquisa foram classificados como baixo, médio e alto nível tecnológico, conforme classificação proposta pelo sistema FAO/Brasileiro (RAMALHO FILHO; BEEK, 1995). No sistema classificado como baixo nível tecnológico, o solo foi preparado com arado de aiveca de tração animal e o controle de plantas daninhas foi realizado por meio de capina manual. Não foram realizadas adubações e o controle de pragas.

No sistema classificado como médio nível tecnológico, o solo foi preparado de forma convencional, 
Tabela 1 - Atributos químicos e texturais na profundidade $0-20 \mathrm{~cm}$ do solo, antes da implantação do experimento em cada nível tecnológico empregado

\begin{tabular}{lccc}
\hline \multirow{2}{*}{ Características } & \multicolumn{3}{c}{ Níveis tecnológicos de manejo } \\
\cline { 2 - 4 } & Baixo & Médio & Alto \\
\hline $\mathrm{pH}(\mathrm{em}$ água) & 7,3 & 7,3 & 7,7 \\
P Mehlich $\left(\mathrm{mg} \mathrm{kg}^{-1}\right)$ & 16,4 & 14,9 & 16,9 \\
P remanescente $\left(\mathrm{mg} \mathrm{L}^{-1}\right)$ & 24,0 & 24,7 & 26,0 \\
$\mathrm{~K}\left(\mathrm{mg} \mathrm{kg}^{-1}\right)$ & 382 & 894 & 353 \\
$\mathrm{Ca}\left(\mathrm{cmol}_{\mathrm{c}} \mathrm{dm}^{-3}\right)$ & 8,60 & 7,40 & 8,80 \\
$\mathrm{Mg}\left(\mathrm{cmol}_{\mathrm{c}} \mathrm{dm}^{-3}\right)$ & 2,00 & 2,00 & 1,20 \\
$\mathrm{Al}\left(\mathrm{cmol}_{\mathrm{c}} \mathrm{dm}^{-3}\right)$ & 0,00 & 0,00 & 0,00 \\
$\mathrm{H}+\mathrm{Al}\left(\mathrm{cmol}_{\mathrm{c}} \mathrm{dm}^{-3}\right)$ & 0,95 & 0,95 & 0,89 \\
$\mathrm{SB}\left(\mathrm{cmol}_{\mathrm{c}} \mathrm{dm}^{-3}\right)$ & 11,58 & 11,69 & 10,90 \\
$\mathrm{t}\left(\mathrm{cmol}_{\mathrm{c}} \mathrm{dm}^{-3}\right)$ & 11,58 & 11,69 & 10,90 \\
$\mathrm{~m}(\%)$ & 0 & 0 & 0 \\
$\mathrm{~T}\left(\mathrm{cmol}_{\mathrm{c}} \mathrm{dm}^{-3}\right)$ & 12,53 & 12,65 & 11,80 \\
$\mathrm{~V}(\%)$ & 92 & 92 & 92 \\
Matéria orgânica $\left(\mathrm{dag} \mathrm{kg}^{-1}\right)$ & 3,23 & 3,08 & 3,23 \\
Textura do solo & Média & Média & Média \\
\hline
\end{tabular}

porém, com apenas uma gradagem, por meio de grade niveladora de tração mecânica. Conforme a análise química do solo aplicaram-se $7 \mathrm{~kg}$ de esterco bovino por metro linear, cuja quantidade foi calculada após a determinação do teor matéria seca, considerando-se a composição de $3,1 \%$ de $\mathrm{N}, 1,8 \%$ de $\mathrm{P}_{2} 0_{5}$ e $2,1 \%$ de $\mathrm{K}_{2} \mathrm{O}$ (COMISSÃO DE FERTILIDADE DO SOLO DO ESTADO DE MINAS GERAIS, 1999). Em cobertura, aplicaram-se, via solo, 10 litros $\mathrm{m}^{-1}$ de biofertilizante, proveniente de um biodigestor anaeróbio, contendo $0,76 \mathrm{~g} \mathrm{~L}^{-1}$ de $\mathrm{N}, 0,96 \mathrm{~g} \mathrm{~L}^{-1}$ de $\mathrm{P}_{2} \mathrm{O}_{5} \mathrm{e}$ $1,32 \mathrm{~g} \mathrm{~L}^{-1}$ de $\mathrm{K}_{2} \mathrm{O}$. O controle de plantas daninhas também foi realizado manualmente. Para o controle de Spodoptera frugiperda (lagarta-do-cartucho) aplicou-se um inseticida à base de óleo de nim (Azadirachta indica A. Juss.), com concentração de $0,7 \%$.

No sistema classificado como alto nível tecnológico, o solo foi preparado por meio de uma aração profunda e duas gradagens de tração mecânica. Baseandose no resultado da análise química do solo, foram aplicados, na ocasião da semeadura, $246,15 \mathrm{~kg} \mathrm{ha}^{-1}$ do formulado (NPK) 4-30-10 e, em cobertura, $500 \mathrm{~kg} \mathrm{ha}^{-1}$ de sulfato de amônio e $20 \mathrm{~kg} \mathrm{ha}^{-1}$ de cloreto de potássio. $\mathrm{O}$ controle de plantas daninhas, cujas espécies de maior ocorrência foram Amaranthus sp., Bidens pilosa e Digitaria horizontalis, foi realizado aplicando-se o equivalente a 5,57 $\mathrm{L} \mathrm{ha}^{-1} \mathrm{de}$ atrazina. Para o controle de Spodoptera frugiperda, aplicouse $0,096 \mathrm{~L} \mathrm{ha}^{-1}$ de triflumurom $\left(480 \mathrm{~g} \mathrm{~L}^{-1}\right)$. A necessidade hídrica das plantas foi suprida por meio da irrigação tipo microaspersão, desde o semeio até o enchimento dos grãos (BERGAMASCHI et al., 2004).

As plantas, pertencentes à parcela útil, foram analisadas quanto às seguintes variáveis: a) porcentagem de emergência, determinada aos 21 dias após a semeadura, antes da operação de desbaste; b) incidência de Spodoptera frugiperda, avaliada aos 30 dias após a semeadura, antes da aplicação dos inseticidas (OLIVEIRA et al., 2007), expressa em porcentagem; c) precocidade do florescimento, obtendo-se o número de dias necessários, a partir da semeadura, para a emissão de $50 \%$ da inflorescência masculina e 50\% da inflorescência feminina; d) sincronia do florescimento, calculada pela diferença entre os períodos necessários para a ocorrência dos florescimentos feminino e masculino, expressa em dias; e) plantas acamadas, computadas aquelas que, no ponto de colheita, apresentaram ângulo entre a base do colmo e o nível do solo inferior a $45^{\circ}$ (SANGOI et al., 2001), expressando os resultados em porcentagem; g) estande final, expresso em plantas ha- $\mathrm{a}^{-1} \mathrm{e}, \mathrm{h}$ ) produtividade $\left(\mathrm{kg} \mathrm{ha}^{-1}\right)$, corrigida para $13 \%$ de umidade. Escolheram-se, aleatoriamente, vinte plantas dentro da parcela útil, nas quais se avaliaram: i) diâmetro do colmo, em milímetro, medido na metade do primeiro entrenó expandido do mesmo; j) altura da planta, em metros, medindo-se do nível do solo à base da inserção da folha bandeira e; 
k) altura da inserção da primeira espiga, expressa em metros

Os dados foram submetidos à análise de variância, sendo aqueles expressos em porcentagem, previamente transformados em arc sen $\sqrt{ }(\mathrm{x} / 100)$ e, aqueles oriundos de contagem, transformados em $\sqrt{ }(\mathrm{x})$. Tais transformações são especialmente recomendadas para dados que estejam nas faixas entre 0 e $20 \%$ ou 80 e $100 \%$ (GOMES, 1990), visando ajustar os dados a uma distribuição normal, aumentando a precisão dos testes empregados. As médias foram comparadas pelo teste de Tukey $(\mathrm{p}<0,05)$.

\section{RESULTADOS E DISCUSSÃO}

Não houve efeito da interação entre os fatores genótipos de milho e sistemas tecnológicos de manejo para as variáveis analisadas (Tabelas 2 e 3), indicando que o desempenho agronômico das plantas não foi afetado de maneira diferenciada entre os genótipos pelos sistemas tecnológicos de manejo.

A porcentagem de emergência das plantas não foi afetada pelos sistemas tecnológicos de manejo, mas sofreu interferência dos genótipos (Tabela 2). O híbrido simples apresentou a menor média, diferenciando-se estatisticamente dos demais (Tabela 4), demonstrando um baixo vigor das sementes utilizadas. A queda no vigor, expressa em condições de campo, mesmo quando a germinação é elevada, influencia diretamente a emergência e o desenvolvimento inicial das plantas, levando a uma queda na população final e na produtividade (ANDREOLI et al., 2002; DIAS; MONDO; CICERO, 2010).

A infestação de Spodoptera frugiperda não foi influenciada pelos diferentes sistemas de manejo (Tabela 2), semelhantemente ao resultado encontrado por Cividanes e Yamamoto (2002) em milho cultivado em sistemas de plantio direto e convencional. Em contrapartida, verificou-se a influência dos genótipos sobre a ocorrência da praga (Tabela 2), onde a variedade crioula 'BR da Várzea' apresentou menor infestação do que o híbrido simples IAC 8333, podendo ser considerada mais resistente, pois conforme definiram Gallo et al. (2002), um genótipo é mais resistente se, devido à sua constituição genotípica, é menos danificada que outras em condições de igualdade para o ataque de uma praga.

Evidenciou-se que, além das características genéticas das plantas, o manejo tecnológico também influenciou a precocidade da cultura do milho (Tabela 2). As plantas cultivadas sob médio nível tecnológico foram mais precoces e, em contrapartida, as cultivadas sob alto nível, foram mais tardias (Tabela 4). No tocante aos genótipos, a variedade crioula 'Argentino' mostrou-se mais tardia. O uso de materiais mais precoces permite a desocupação da área antecipadamente, aumentando a capacidade de exploração, mas conforme o caso, isso nem sempre é sinônimo de maiores rendimentos. Materiais mais precoces dispõem de menos tempo para se recuperar de restrições ambientais impostas ao aparato fotossintético da planta nas fases de pré-floração, floração e início de enchimento de grãos (SANGOI et al., 2001). Com isso, no Norte de Minas Gerais, onde as chuvas são mal distribuídas e no segmento da agricultura familiar, onde boa parte da produção de milho é realizada sem irrigação, pode ser mais apropriado o emprego de materiais mais tardios.

As plantas cultivadas sob baixo nível tecnológico apresentaram menor sincronia entre os florescimentos que aquelas cultivadas sob alto nível tecnológico (Tabela 4). Isso já demonstra uma tendência das plantas cultivadas sob baixo nível tecnológico em apresentarem menor produtividade em relação àquelas cultivadas sob alto nível tecnológico, pois o menor sincronismo entre os florescimentos leva a um decréscimo do número de grãos por espiga na ordem de 8 a 32\% (CÁRCOVA et al., 2000). O híbrido duplo apresentou a maior sincronia e, a variedade crioula 'Argentino', a menor. A redução no sincronismo dos

Tabela 2 - Resumo da análise de variância (valores de 'F') para emergência (EME), incidência de Spodoptera frugiperda (ISF), florescimento masculino (FM) e feminino (FF), sincronia entre os florescimentos (SF) e acamamento (ACA) das plantas em função de sistemas tecnológicos de manejo e de genótipos de milho

\begin{tabular}{|c|c|c|c|c|c|c|c|}
\hline \multirow{2}{*}{ Fonte de variação } & \multirow{2}{*}{ GL } & \multicolumn{6}{|c|}{ Quadrado Médio } \\
\hline & & EME & ISF & FM & FF & SF & $\mathrm{ACA}$ \\
\hline Sistemas de manejo (SM) & 2 & $0,36^{\mathrm{ns}}$ & $1,89^{\mathrm{ns}}$ & $21,68 * *$ & $10,95 * *$ & $5,17 *$ & $6,76^{*}$ \\
\hline Genótipos (GE) & 3 & $11,12 * *$ & $5,04 *$ & $60,27 * *$ & $96,48 * *$ & $66,03 * *$ & $10,20 * *$ \\
\hline SM x GE & 6 & $1,04^{\mathrm{ns}}$ & $0,36^{\mathrm{ns}}$ & $0,37^{\mathrm{ns}}$ & $0,79^{\text {ns }}$ & $2,51^{\mathrm{ns}}$ & $1,20^{\mathrm{ns}}$ \\
\hline $\mathrm{CV}(\%)$ & & 12,90 & 19,58 & 1,84 & 2,55 & 29,0 & 45,18 \\
\hline
\end{tabular}

ns, Não significativo; *, **, $\mathrm{p}<0,01$ e $\mathrm{p}<0,05$, respectivamente, pelo teste $\mathrm{F}$ 
Tabela 3 - Resumo da análise de variância (valores de 'F') para diâmetro do colmo (DC), altura das plantas (AP), altura de inserção da primeira espiga (AIE), estande final (EF) e produtividade (PROD) das plantas em função de sistemas tecnológicos de manejo e de genótipos de milho

\begin{tabular}{lcccccc}
\hline \multirow{2}{*}{ Fonte de variação } & \multirow{2}{*}{ GL } & \multicolumn{5}{c}{ Quadrado Médio } \\
\cline { 3 - 6 } & & DC & AP & AIE & EF & PROD \\
\hline Sistemas de manejo (SM) & 2 & $0,59^{\text {ns }}$ & $1,98^{\text {ns }}$ & $5,07^{*}$ & $0,97^{\text {ns }}$ & $23,15^{* *}$ \\
Genótipos (GE) & 3 & $2,70^{\text {ns }}$ & $19,59^{* *}$ & $51,34^{* *}$ & $13,59^{* *}$ & $21,69^{* *}$ \\
SM x GE & 6 & $0,42^{\text {ns }}$ & $0,49^{\text {ns }}$ & $0,58^{\text {ns }}$ & $0,98^{\text {ns }}$ & $0,79^{\text {ns }}$ \\
CV $(\%)$ & & 8,00 & 7,37 & 11,58 & 5,40 & 17,00 \\
\hline
\end{tabular}

${ }_{\text {ns }}$, Não significativo; *, **, $\mathrm{p}<0,01$ e $\mathrm{p}<0,05$, respectivamente, pelo teste $\mathrm{F}$

Tabela 4 - Valores médios da emergência (EME), incidência de Spodoptera frugiperda (ISF), florescimento masculino (FM) e feminino (FF), sincronia entre os florescimentos (SF) e acamamento (ACA) das plantas em função de sistemas tecnológicos de manejo e de genótipos de milho

\begin{tabular}{|c|c|c|c|c|c|c|c|}
\hline $\begin{array}{ll}\text { Sistemas } & \begin{array}{l}\text { tecnológicos } \\
\text { manejo }\end{array}\end{array}$ & de & $\mathrm{EME}^{1}$ & ISF $^{1}$ & FM (dias) & FF (dias) & SF (dias) & $\mathrm{ACA}^{1}$ \\
\hline Baixo & & $1,04(74,54) \mathrm{A}$ & $0,84(55,07) \mathrm{A}$ & $59,17 \mathrm{~B}$ & $63,08 \mathrm{~A}$ & $3,92 \mathrm{~A}$ & $0,49(21,81) \mathrm{A}$ \\
\hline Médio & & $1,06(76,27) \mathrm{A}$ & $0,93(64,23) \mathrm{A}$ & $57,50 \mathrm{C}$ & $60,50 \mathrm{~B}$ & $3,00 \mathrm{AB}$ & $0,47(20,73) \mathrm{A}$ \\
\hline Alto & & $1,04(74,47) \mathrm{A}$ & $0,81(52,90) \mathrm{A}$ & $60,42 \mathrm{~A}$ & $63,17 \mathrm{~A}$ & $2,75 \mathrm{~B}$ & $0,26(6,66) \mathrm{B}$ \\
\hline \multicolumn{8}{|l|}{ Genótipos } \\
\hline 'Argentino' & & $1,09(78,70) \mathrm{A}$ & $0,93(64,19) \mathrm{AB}$ & $63,22 \mathrm{~A}$ & $70,00 \mathrm{~A}$ & $6,7 \mathrm{~A}$ & $0,61(32,68) \mathrm{A}$ \\
\hline 'BR da Várzea' & & $1,11(80,56) \mathrm{A}$ & $0,74(45,44) \mathrm{B}$ & $57,44 \mathrm{~B}$ & $60,11 \mathrm{~B}$ & $2,56 \mathrm{~B}$ & $0,35(12,08) \mathrm{B}$ \\
\hline Híb. duplo & & $1,17(85,00) \mathrm{A}$ & $0,78(49,76) \mathrm{AB}$ & $58,11 \mathrm{~B}$ & $60,00 \mathrm{~B}$ & $0,78 \mathrm{C}$ & $0,22(4,97) \mathrm{B}$ \\
\hline Híb. simples & & $0,85(56,11) \mathrm{B}$ & $1,00(71,21) \mathrm{A}$ & $57,33 \mathrm{~B}$ & $58,89 \mathrm{~B}$ & $2,78 \mathrm{~B}$ & $0,41(15,87) \mathrm{B}$ \\
\hline
\end{tabular}

${ }^{1}$ Médias seguidas de mesma letra na coluna não diferem estatisticamente entre si pelo teste de Tukey (p<0,05); ${ }^{1}$ médias oriundas da transformação dos dados em arc sen $\sqrt{ }(\mathrm{x} / 100)$. Os valores entre parênteses correspondem às médias originais, dados em porcentagem

florescimentos da variedade 'Argentino' pode indicar fraca adaptação a altas populações de plantas (SANGOI et al., 2001), visto que, nesta pesquisa, a população de plantas utilizada foi alta (62.500 plantas ha $\left.{ }^{-1}\right)$, acima do indicado para os genótipos não melhorados.

Houve maior acamamento nas plantas cultivadas sob o baixo e o alto níveis tecnológicos (Tabela 4). Quanto aos genótipos, a variedade 'Argentino' demonstrou maior susceptibilidade ao acamamento. Esse resultado era esperado, pois como enfatizam Machado et al. (2003), apesar das variedades locais possuírem uma relevante importância, sobretudo como fonte de germoplasma, possuem, às vezes, características indesejáveis, tais como o porte das plantas, ciclo e suscetibilidade ao acamamento. A arquitetura de plantas dos híbridos modernos contribui para reduzir a sua suscetibilidade ao acamamento, principalmente devido à maior precocidade, à menor estatura de plantas, à menor área foliar e à presença de folhas mais curtas e eretas (SANGOI et al., 2001).
O resultado da análise de variância para diâmetro de colmo não foi significativo pelo teste de $F$ para ambos os fatores (Tabela 3). Segundo Cruz et al. (2008) a adubação de semeadura favorece o maior diâmetro do colmo, o que não foi evidenciado nesta pesquisa, visto que não houve adubação de semeadura nas plantas sob baixo nível tecnológico.

Os sistemas de manejo também não interferiram na altura das plantas (Tabela 3), concordando com o que foi observado por Vaz de Melo et al. (2007) em diferentes sistemas de manejo orgânico e convencional. Custódio, Pasqualetto e Oliveira (2003) verificaram que cada genótipo responde de maneira distinta ao sistema de manejo empregado, sendo que alguns apresentaram maior altura e outros foram indiferentes. Quanto à altura de inserção da espiga, as plantas cultivadas sob alto nível tecnológico apresentaram menor estatura que aquelas cultivadas sob médio nível tecnológico (Tabela 5). Esse resultado contrasta daqueles obtidos por Custódio, Pasqualetto e Oliveira (2003), que verificaram 
Tabela 5 - Valores médios de diâmetro do colmo (DC), altura das plantas (AP), altura de inserção da primeira espiga (AIE), do estande final (EF) e da produtividade (PROD) das plantas em função de sistemas tecnológicos de manejo e de genótipos de milho

\begin{tabular}{lcclcc}
\hline Sistemas tecnológicos de manejo & DC $(\mathrm{mm})$ & $\mathrm{AP}(\mathrm{m})$ & $\mathrm{AIE}(\mathrm{m})$ & $\mathrm{EF}^{1}$ & PROD $\left(\mathrm{kg} \mathrm{ha}^{-1}\right)$ \\
\hline Baixo & $20,22 \mathrm{~A}$ & $2,08 \mathrm{~A}$ & $1,23 \mathrm{~A}$ & $236,85(56.423,6) \mathrm{A}$ & $6.566,02 \mathrm{~A}$ \\
Médio & $20,86 \mathrm{~A}$ & $2,18 \mathrm{~A}$ & $1,15 \mathrm{AB}$ & $233,96(55.034,7) \mathrm{A}$ & $5.239,23 \mathrm{~B}$ \\
Alto & $20,24 \mathrm{~A}$ & $2,06 \mathrm{~A}$ & $1,05 \mathrm{~B}$ & $241,22(58.506,9) \mathrm{A}$ & $4.068,46 \mathrm{C}$ \\
\hline Genótipos & & & & & \\
\hline 'Argentino' & $21,41 \mathrm{~A}$ & $2,43 \mathrm{~A}$ & $1,60 \mathrm{~A}$ & $237,80(56.713,0) \mathrm{A}$ & $3.423,83 \mathrm{C}$ \\
'BR da Várzea' & $19,99 \mathrm{~A}$ & $2,09 \mathrm{~B}$ & $1,09 \mathrm{~B}$ & $246,18(60.648,1) \mathrm{A}$ & $6.019,43 \mathrm{AB}$ \\
Híb. duplo & $19,43 \mathrm{~A}$ & $1,97 \mathrm{~B}$ & $0,98 \mathrm{BC}$ & $250,35(62.731,5) \mathrm{A}$ & $6.631,06 \mathrm{~A}$ \\
Híb. simples & $20,93 \mathrm{~A}$ & $1,93 \mathrm{~B}$ & $0,90 \mathrm{C}$ & $215,05(46.527,8) \mathrm{B}$ & $5.090,61 \mathrm{~B}$ \\
\hline
\end{tabular}

Médias seguidas de mesma letra na coluna não diferem estatisticamente entre si pelo teste de Tukey $(\mathrm{p}<0,05)$; ${ }^{1}$ médias oriundas da transformação dos dados em $\sqrt{x}$. Os valores entre parênteses correspondem às médias originais, dados em plantas ha-1

que a altura de inserção da espiga nas plantas foi maior naquelas cultivadas sob sistema correspondente ao maior nível tecnológico de manejo nesta pesquisa.

A variedade crioula 'Argentino' apresentou a maior altura de plantas, diferenciando-se estatisticamente das demais (Tabela 5). Quanto à altura da inserção das espigas, novamente a variedade 'Argentino' apresentou o maior valor (Tabela 5) e, a variedade 'BR da Várzea', apresentou um valor mediano. Essa diferença pode ser explicada pelo fato do porte mais baixo ser um dos objetivos do melhoramento genético, visando a melhor adequação das plantas para a colheita mecânica. De maneira geral, quanto maior a precocidade de um genótipo, menor é o seu número de folhas expandidas na antese, menor a sua área foliar e mais reduzida é a estatura final da planta (ALMEIDA et al., 2000). Essa informação foi confirmada nesta pesquisa ao se confrontar os resultados obtidos com as análises da precocidade (Tabela 4) e do porte das plantas da variedade 'Argentino' (Tabela 5). $\mathrm{O}$ estande estabelecido e a maior altura das plantas e da inserção das espigas dessa variedade podem também estar relacionados à maior porcentagem de plantas acamadas (Tabela 4). Devido ao genótipo 'Argentino' se tratar de uma variedade crioula e ao 'BR da Várzea' ter sofrido seleção massal por mais de dez anos, a partir da variedade BR 106, a altura pode não ter sido alvo de seleção pelos agricultores. Nesse sentido, Pantaleão e Freitas Sobrinho (2007) destacaram que a maior produção de matéria fresca dessas plantas é um aspecto relevante, principalmente na agricultura camponesa da região semiárida brasileira, onde é comum a utilização desse material como subproduto na alimentação animal. Além disso, a maior produção de massa também é vantajosa em sistemas de cultivo que utilizam cobertura morta no solo que, segundo Souza, Montenegro e Montenegro (2008), é uma prática recomendada em regiões semiáridas, contribuindo para a melhoria do desempenho das culturas, redução das perdas de água do solo e redução da erosão superficial.

O estande final das plantas não sofreu influência dos diferentes níveis tecnológicos de manejo empregados, porém foi influenciado pelos genótipos (Tabela 3). Cortez, Furlani e Silva (2009) igualmente observaram que diferentes sistemas de adubação e de consórcio não interferem na consolidação do estande da cultura em estudo. Quanto aos genótipos, verificou-se que o híbrido simples apresentou estande inferior (Tabela 5). Esse resultado enfatiza a hipótese do baixo vigor do lote de sementes desse genótipo.

A maior produtividade foi alcançada pelas plantas cultivadas sob alto nível tecnológico e a menor, por aquelas cultivadas sob baixo nível tecnológico (Tabela 5). A menor produtividade das plantas sob baixo nível tecnológico pode ser reflexo da baixa sincronia entre os florescimentos, da menor precocidade e do maior índice de acamamentos, posto que essas características interferem diretamente a produção de grãos. Strieder et al. (2008), por outro lado, notaram que a produtividade não foi afetada pelos sistemas de manejo. Não obstante, diversos outros autores obtiveram resultados semelhantes aos obtidos nesta pesquisa (FORSTHOFER et al., 2006; KANEKO et al., 2010; SANGOI et al., 2003). Silva et al. (2007) notaram que o sistema orgânico não apenas apresentou produtividade superior ao sistema sem adubação, mas também ao sistema convencional, concordando, em parte, com os resultados desta pesquisa, onde o emprego do médio nível tecnológico, de manejo orgânico, aumentou em $28,78 \%$ a produtividade em relação ao emprego do baixo nível tecnológico, porém, o emprego do alto nível tecnológico, incrementou a produtividade em $25,32 \%$ em 
relação ao médio nível. Cruz et al. (2006) demonstraram que a aplicação de adubação orgânica para o cultivo de milho forneceu quantidade de nutrientes suficiente para incrementar a produtividade, mesmo no primeiro ano de aplicação, como foi o caso do experimento em questão.

Pela produtividade ter sido afetada isoladamente por ambos os fatores testados (Tabela 3), pode-se inferir que, de maneira geral, as variedades crioulas utilizadas nesta pesquisa foram capazes de responder positivamente à aplicação de tecnologia no manejo da cultura tanto quanto os híbridos. Diferenciando-se estatisticamente dos demais genótipos, a variedade crioula 'Argentino' apresentou a menor produtividade (Tabela 5), situando-se abaixo da média nacional, que foi $3.715 \mathrm{~kg} \mathrm{ha}^{-1}$ na safra 2009/2010 (INSTITUTO BRASILEIRO DE GEOGRAFIA E ESTATÍSTICA, 2010). Porém a sua produtividade foi superior à média municipal de Montes Claros/MG, que foi de $1.980 \mathrm{~kg} \mathrm{ha}^{-1}$ na safra 2007/2008 (INSTITUTO BRASILEIRODEGEOGRAFIAEESTATÍSTICA, 2010). A menor produtividade do 'Argentino' era um resultado esperado, pois está coerente com os resultados das demais variáveis analisadas. Pelo fato desse genótipo ter apresentado o florescimento feminino tardiamente em relação aos demais, e ter apresentado uma sincronia entre florescimentos muito baixa, no momento da fecundação, possivelmente, a disponibilidade de pólens no ambiente não foi satisfatória.

O híbrido simples, apesar de ser um material altamente produtivo, não se destacou em produtividade, apresentando valores medianos. Esse resultado foi influenciado principalmente pela baixa emergência (Tabela 4) e pelo baixo estande final (Tabela 5).

A média da produtividade alcançada pela variedade crioula 'BR da Várzea' não se diferenciou estaticamente dos híbridos. A sua produtividade superou em $62,03 \%$ a média nacional, apresentando desempenho agronômico desejável e capacidade de expressar o seu potencial produtivo em sistemas de manejo sob baixo, médio e alto níveis tecnológicos. Esse resultado contrasta com aquele encontrado por Brito et al. (2005), que afirmam que os híbridos apresentam maior produtividade que as variedades. Meneguetti, Girardi e Reginatto (2002), por outro lado, ao realizarem ensaios com diferentes genótipos de milho, verificaram desempenho semelhante ou até mesmo superior das variedades crioulas em relação às variedades comerciais e híbridos. Machado et al. (2003), ao avaliarem 25 variedades comerciais e crioulas de milho, quanto ao uso eficiente do $\mathrm{N}$, também observaram que houve um incremento na produtividade. Esses autores ainda notaram que as variedades comerciais demonstraramse mais produtivas que as crioulas, contudo, sob solo com baixo teor de $\mathrm{N}$, as variedades crioulas sobressaíram, o que confirma a maior adaptabilidade das mesmas.
Analisando conjuntamente todos os resultados, nota-se que, de maneira geral, as variedades crioulas foram capazes de responder ao incremento tecnológico na lavoura, tanto quanto os cultivares modernos. Práticas de manejo acessíveis, como a utilização de adubação orgânica e a aplicação de caldas naturais para o controle de pragas, são capazes de maximizar a produção de grãos de milho, o que proporciona maior rentabilidade ao agricultor familiar.

\section{CONCLUSÕES}

1. Na cultura do milho, cada característica agronômica sofre influência de modo diferenciado frente aos diferentes níveis tecnológicos de manejo, sendo independente do material genético;

2. O desempenho agronômico das variedades crioulas é maximizado pelo incremento tecnológico no manejo, tanto quanto os híbridos. A adubação orgânica e o manejo alternativo de pragas são capazes de maximizar a produtividade em milho.

\section{AGRADECIMENTOS}

À CAPES e à FAPEMIG, pela concessão de bolsas de mestrado ao primeiro e terceiro autores, respectivamente; ao $\mathrm{CNPq}$, pelo auxílio financeiro; aos Sindicatos dos Trabalhadores Rurais de Porteirinha e de Varzelândia, pela doação das sementes das variedades crioulas.

\section{REFERÊNCIAS}

ALMEIDA, M. L. de. et al. Incremento na densidade de plantas: uma alternativa para aumentar o rendimento de grãos de milho em regiões de curta estação estival de crescimento. Ciência Rural, v. 30, n. 1, p. 23-29, 2000.

ANDREOLI, C. et al. Influência da germinação da semente e da densidade de semeadura no estabelecimento do estande e na produtividade de milho. Revista Brasileira de Sementes, v. 24, n. 2, p. 1-5, 2002.

BERGAMASCHI, H. et al. Distribuição hídrica no período crítico do milho e produção de grãos. Pesquisa Agropecuária Brasileira, v. 39, n. 9, p. 831-839, 2004.

BOEF, W. S. Biodiversidade e agrobiodiversidade. In: BOEF, W. S. et al. (Org.) Biodiversidade e agricultores: fortalecendo o manejo comunitário. Porto Alegre: L\&PM, 2007. cap. 2, p. 36-40.

BRITO, A. R. de M. B. et al. Adaptabilidade e estabilidade de cultivares de milho no Estado de Pernambuco. Revista Ciência Agronômica, v. 36, n. 3, p. 348-353, 2005. 
CÁRCOVA, J. et al. Synchronous pollination within and between ears improves kernel set in maize. Crop Science, v. 40, n. 4, p. 1056-1061, 2000.

CIVIDANES, F. J.; YAMAMOTO, F. T. Pragas e inimigos naturais na soja e no milho cultivados em sistemas diversificados. Scientia Agricola, v. 59, n. 4, p. 683-687, 2002.

COMISSÃO DE FERTILIDADE DO SOLO DO ESTADO DE MINAS GERAIS. Adubação orgânica. In: RIBEIRO, A. C.; GUIMARÃES, P. T. G.; ALVARES VENEGAS, V. H. (Ed.). Recomendação para o uso de corretivos e fertilizantes em Minas Gerais: 5 aproximação. Viçosa: CFSEMG, 1999. p. 87-92.

CORTEZ, J. W.; FURLANI, C. E. A.; SILVA, R. P. da. Sistemas de adubação e consórcio de culturas intercalares e seus efeitos nas variáveis de colheita da cultura do milho. Engenharia Agrícola, v. 29, n. 2, p. 277-287, 2009.

CRUZ, J. C. et al. Produção de milho orgânico na agricultura familiar. Embrapa Sorgo e Milho, 2006. 17 p. (Circular Técnica, 81).

CRUZ, S. C. S. et al. Adubação nitrogenada para o milho cultivado em sistema plantio direto, no Estado de Alagoas. Revista Brasileira Engenharia Agrícola e Ambiental, v. 12, n. 1, p. $62-68,2008$

CUSTÓDIO, D. P.; PASQUALETTO, A.; OLIVEIRA, I. P. de. Comportamento de cultivares de milho (Zea mays) e sistemas de cultivo. Estudos, v. 30, n. 8, p. 1793-1803, 2003.

DIAS, M. A. N.; MONDO, V. H. V., CICERO, S. M. Vigor de sementes de milho associado à mato-competição. Revista Brasileira de Sementes, v. 32, n. 2, p. 93-101, 2010.

FORSTHOFER, E. L. et al. Desempenho agronômico e econômico do milho em diferentes níveis de manejo e épocas de semeadura. Pesquisa Agropecuária Brasileira, v. 41, n. 3, p. 399-407, 2006.

GALLO, D. et al. Entomologia Agrícola. 3. ed. Piracicaba: FEALQ, 2002. 920 p.

INSTITUTOBRASILEIRODE GEOGRAFIAEESTATÍSTICA. Levantamento Sistemático da Produção agrícola. Disponível em: <http://www.ibge.gov.br>. Acesso em: 17 out. 2010.

GOMES, F. P. Curso de estatística experimental. Piracicaba: ESALQ, 1990. 467 p.

KANEKO, F. H. et al. Manejo do solo e do nitrogênio em milho cultivado em espaçamentos reduzido e tradicional. Bragantia, v. 69, n. 3, p. 677-686, 2010.
MACHADO, A. T. et al. Resposta de variedades de milho a níveis e fontes de nitrogênio. Planaltina: Embrapa Cerrados, 2003. 27 p. (Boletim de Pesquisa e Desenvolvimento, 93).

MENEGUETTI, G. A.; GIRARDI, J. L.; REGINATTO, J. C. Milho crioulo: tecnologia viável e sustentável. Agroecologia e Desenvolvimento Sustentável, v. 3, n. 1, p. 12-17, 2002.

OLIVEIRA, M. S. S. et al. Eficiência de produtos vegetais no controle da lagarta-do-cartucho-do-milho Spodoptera frugiperda (JE Smith, 1797) (Lepidoptera: Noctuidae). Ciência e Agrotecnologia, v. 31, n. 2, p. 326-331, 2007.

PANTALEÃO, M. J.; FREITAS SOBRINHO, J. D. Sementes da vida: camponeses resgatando as sementes crioulas em Goiás. Agriculturas, v. 4, n. 3, p. 10-12, 2007.

RAMALHO FILHO, A.; BEEK, K. J. Sistema de avaliação da aptidão agrícola das terras. 3. ed. Rio de Janeiro: Empresa Brasileira de Pesquisa Agropecuária, 1995. 65 p.

RIBEIRO, N. A. et al. Incidência de podridões do colmo, grãos ardidos e produtividade de grãos de genótipos de milho em diferentes sistemas de manejo. Ciência Rural, v. 21, n. 1, p. 1003-1009, 2005.

SANGOI, L. et al. Desempenho de híbridos de milho com ciclos contrastantes em função da desfolha e da população de plantas. Scientia Agricola, v. 58, n. 2, p. 271-276, 2001.

SANGOI, L. et al. Níveis de manejo na cultura do milho em dois ambientes contrastantes: análise técnico-econômica. Ciência Rural, v. 33, n. 6, p. 1021-1029, 2003.

SILVA, R.G. et al. Produtividade de milho em diferentes sistemas produtivos. Revista Verde de Agroecologia e Desenvolvimento Sustentável, v. 2, n. 2, p. 136-141, 2007.

SOUZA; E. R. de; MONTENEGRO, A. A. de A.; MONTENEGRO, S. M. G. L. Variabilidade espacial da umidade do solo em Neossolo Flúvico. Revista Brasileira de Recursos Hídricos, v. 13, n. 2, p. 177-187, 2008.

STRIEDER, M. L. et al. Crop management systems and maize grain yield under narrow row spacing. Scientia Agricola, v. 65, n. 4, p. 346-353, 2008.

VAZ DE MELO, A. et al. Dinâmica populacional de plantas daninhas em cultivo de milho-verde nos sistemas orgânico e tradicional. Planta Daninha, v. 25, n. 3, p. 521-527, 2007.

ZIMMERMANN, F. J. P. Estatística aplicada à pesquisa agrícola. Santo Antônio de Goiás: Embrapa Arroz e feijão, 2004. 402 p. 